\title{
Die Aktivität von Renin im Serum der Frau während der Schwangerschaft und während des menstruellen Zyklus
}

\author{
Von H. Kaulhausen, Hannelore Schmidi ${ }^{1}$ ), H. Lindstaedt und H. Breuer \\ Aus dem Institut für Klinische Biochemie und Klinische Chemie der Universität Bonn
}

(Eingegangen am 3. November 1971)

Bei 13 Schwangeren (mens IV bis X) sowie bei vier weiblichen Normalpersonen während des menstruellen Zyklus wurde die Reninaktivität im Serum mit Hilfe einer biologischen Methode bestimmt. In der Schwangerschaft war die Reninaktivität auf das 1,5 bis 6fache erhöht; eine Korrelation zur Höhe des Blutdrucks war nicht feststellbar.

Durch Verlaufsbeobachtungen in 2-3tägigen Abständen konnte sowohl zum Zeitpunkt der Ovulation als auch während der Lutealphase ein Maximum der Reninaktivität nachgewiesen werden. Folgende Faktoren werden zur Erklärung der erhöhten Reninaktivität herangezogen:

(1) Infolge der vermehrten Östrogenbildung wird Aldosteron in verstärktem Maße an Plasmaproteine gebunden; dadurch kommt es zu einer Abnahme von freiem Aldosteron und infolgedessen auch der Natriumkonzentration im Serum.

(2) Auch ein erhöhter Progesteronspiegel kann zu einer vermehrten Rückresorption von Natrium im distalen Tubulus und damit zu einet Stimulierung der Reninsekretion führen.

(3) Die östrogenbedingte Erhöhung der Reninsubstratkonzentration im Serum dürfte ebenfalls zu einer vermehrten Bildung von Angiotensin - zumindest während der Schwangerschaft - beitragen.

Besonders in Seren mit hoher Reninaktivität wurden deutlich meßbare „Leeraktivitäten“ beobachtet; diese "Leeraktivitäten“, die auf unvollständige Inaktivierung des endogenen Reninsubstrates während der Dialyse der Serumproben bei pH 3,3 zurückzuführen sind, haben jedoch keinen Einfluß auf die Analysenergebnisse.

\section{The renin activity in serum of women during pregnancy and during the menstrual gycle}

Renin activity was measured by a biological method in the serum of 13 pregnant women (mens IV-X) and 4 normal females during their menstrual cycles. During pregnancy, renin activity was 1.5 to 6 -fold higher than the levels found in nonpregnant females. There was no correlation between renin activity and blood pressure. Continuous measurements every $2-3$ days revealed a maximum of renin activity at the time of ovulation and during the luteal phase of the cycle. The following factors may explain the increased renin activity in these various endocrinological states:

(1) Oestrogens may result in an increase of plasma proteins binding aldosterone, thus decreasing the concentration of free aldosterone; this, in term, decreases sodium concentration in the serum.

(2) Increased progesterone levels may also result in decreased reabsorption of sodium in the distal tubules of the kidney, leading to a stimulation of renin secretion.

(3) The renin substrate concentration increased by oestrogen may play a role in the increased production of angiotensin - at least during pregnancy.

Serum with high renin activity revealed clearly measurable "blank values"; these "blank values", which were produced by incomplete inactivation of the endogenous renin substrate during dialysis of serum at $\mathrm{pH} 3.3$, did not influence the results.

Seit BROwN und Mitarbeiter (1) 1963 erstmalig die Reninaktivität im Serum von Schwangeren bestimmten, sind mit unterschiedlichen Verfahren zahlreiche Untersuchungen $\mathrm{zu}$ verschiedenen Zeitpunkten der Schwangerschaft durchgeführt worden $(2-7)$. Úbereinstimmend wurde eine erhöhte Plasmareninaktivität angegeben. So stellte WINER (2) eine zwei- bis achtfach erhöhte Reninaktivität bei Frauen in der Zeit zwischen der 6. und 40. Schwangerschaftswoche fest, während Gordon und Mitarbeiter (7) eine statistisch signifikante Erhöhung im 2. Trimenon und GeelHoED und VANDER (6) erhöhte Werte im 3. Trimenon fanden. Nach den Beobachtungen von BRown und Mitarbeitern (4) scheint die Reninaktivität während der Schwanger-

Enzym: Renin (EC 3.4.4.15).

1) Teil der Dissertation Hannelore Schmidt, Medizinische Pakultät der Universität Bonn. schaft nicht kontinuierlich anzusteigen. Bei drei Schwangeren lagen die Reninwerte zwischen der 20. und 30. Woche niedriger als zu Beginn oder gegen Ende der Schwangerschaft. Helmer und Judson (5) bestimmten neben der Reninaktivität gleichzeitig auch die Konzentration des Reninsubstrats im Plasma; diese war in der 8. Schwangerschaftswoche auf das Doppelte und zwischen der 32. und 40. Woche auf das Vierfache erhöht.

Bisher liegen nur wenige Angaben über die Reninaktivität während des Menstruationszyklus vor $(2,8,9)$. Brown und Mitarbeiter ( 8 ) bestimmten bei neun Frauen in einwöchigen Abständen die Plasmareninaktivität und beobachteten bei zwei Frauen in der 3. Woche, bei drei weiteren in der 4. Woche deutlich erhöhte Werte. WINER (2) fand bei 10 Frauen, daß die Reninaktivität während der ersten Tage des Zyklus niedrig 
war und allmählich bis zu einem Gipfel in der 4. Woche anstieg. Bei sechs Frauen bestimmten SKINNER und Mitarbeiter (9) die Reninaktivität jeweils am Ende der Menstruationsblutung, in der Zyklusmitte sowie während der Lutealphase. Alle sechs Frauen zeigten in der Lutealphase einen Anstieg der Plasmareninaktivität; lediglich bei einer Versuchsperson war die Reninaktivität in der Zyklusmitte deutlich höher als während der Lutealphase. Das Reninsubstrat blieb bei allen untersuchten Frauen während des Menstruationszyklus unverändert (9).

In den bisherigen Untersuchungen waren die $\mathrm{Ab}-$ stände zwischen den einzelnen Bestimmungen relativ groß; aus diesem Grunde sind unsere Kenntnisse über das Verhalten der Reninaktivität während des menstruellen Zyklus noch lückenhaft. Es schien daher notwendig, Reninbestimmungen in kurzen Zeitabständen während des Menstruationszyklus durchzuführen, um die Wechselwirkungen zwischen Sexualendokrinium und Reninaktivität besser verstehen zu können.

In der vorliegenden Arbeit werden Verlaufsbeobachtungen über die Reninaktivität im Zyklus mitgeteilt; die Ergebnisse lassen ein charakteristisches Verhalten erkennen. Außerdem wird auf die Frage der sogenannten Leeraktivitäten näher eingegangen.

\section{Methodik}

\section{Prinzip des Verfabrens zur Bestimmung der Serumtreninaktivität}

Die Messung der Reninaktivität im Serum erfolgte in Anlehnung an das früher angegebene Verfahren zur Bestimmung von Renin (10). Aus methodischen Gründen wurden die Bestimmungen nicht im Plasma, sondern im Serum durchgeführt. Als Reninsubstrat diente während einer 20stdg. Inkubation das Plasma beidseitig nephrektomierter, männlicher Katzen. Die sowohl in den zu untersuchenden Serumproben als auch im Reninsubstrat enthaltenen sogenannten Angiotensinasen wurden zuvor durch Dialysen gegen EDTA-haltige Pufferlösungen bei niedrigen pH-Werten $(3,3$ bzw. 3,9$)$ inaktiviert. Das während der Inkubation freigesetzte Angiotensin II wurde im Blutdruckversuch bei der Ratte in Form eines "Bracket Assay" bestimmt (Einzelheiten vgl. 1. c. (10))

\section{Enz'm-Einbeit}

Eine Renin-Einheit (R. E.) ist diejenige Reninaktivität in $0,5 \mathrm{ml}$ Serum, die unter Zusatz von $0,2 \mathrm{ml}$ Reninsubstrat (Katzenplasma) während einer 20 stdg. Inkubation bei $37^{\circ} \mathrm{C} 1 \mathrm{ng}$ Angiotensin II freisetzt.

\section{Scbwangere}

Die Seren stammten von 13 gesunden Schwangeren (Alter 19 bis 40 Jahre). Die Blutentnahmen erfolgten zwischen der 16. und 41. Schwangerschaftswoche.

\section{Normalpersonen wäbrend des Menstruationsquklus}

Die Untersuchungen wurden an vier gesunden Frauen (Alter 18-23 Jahre) durchgeführt. Keine der Versuchspersonen wurde mit oralen Kontrazeptiva oder anderen Hormonpräparaten behandelt. Die erste und die letzte Blutentnahme erfolgte jeweils am ersten Tag der Menstruationsblutung. Die Blutentnahmen exfolgten bei den einzelnen Versuchspersonen jeweils zur gleichen Tageszeit (zwischen 10-13 Uhr).

Männlicbe Vergleichspersonen

Die Seren stammten von acht gesunden, normotonen Männern (Alter 23-27 Jahre).

\section{Ergebnisse}

Aktivität von Renin im Serum wäbrend der Scbwangerschaft

Wie aus Abbildung 1 hervorgeht, war die Reninak-. tivität der untersuchten Schwangeren zwischen der 16. und 41. Schwangerschaftswoche gegenüber nichtschwangeren Frauen auf das 1,5- bis 6 fache erhöht. Eine Korrelation zum gleichzeitig gemessenen Blutdruck konnte nicht nachgewiesen werden. Wurde anstelle von Reninsubstrat 0,9proz. NaCl-Lösung zugesetzt, so konnten auch unter diesen Bedingungen im Rattenblutdruckversuch zum Teil erhebliche pressorische Aktivitäten (endogene „Leeraktivität") nachgewiesen werden.

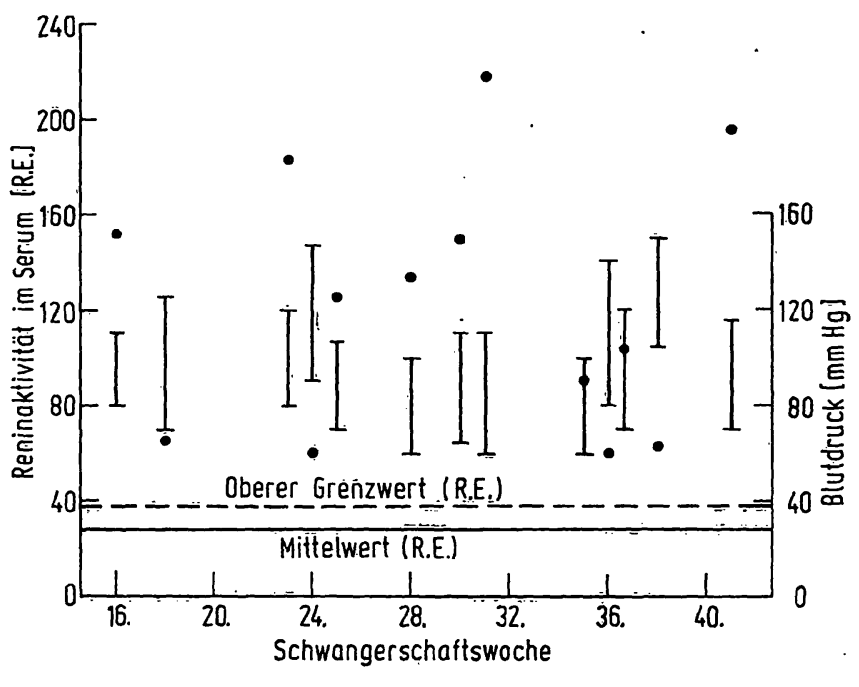

Abb. 1

Aktivität von Renin im Serum sowie Blutdruckwerte bei 13 schwangeren Frauen zwischen der 16. und 41. Woche der Schwangerschaft. Mittelwert sowie oberer Grenzwert der Reninaktivität bei Normalpersonen sind ebenfäls eingetragen. Es wurde das während einer 20stdg. Inkubation mit Reninsubstrat (Katzenplasma) entstandene Angiotensin II im Rattenblutdruckversuch gemessen

\section{Aktivität von Renin im Serum wäbrend des Menstruations-} zyklus

Bei zwei Frauen (Abb. 2 u. 3) wurde zum Zeitpunkt des Anstiegs der Basaltemperatur ein Maximum der Serumreninaktivität beobachtet; bei beiden Versuchspersonen wurde ein zweites Maximum während der Lutealphase festgestellt. Bei der dritten Versuchsperson (Abb. 4) zeigte sich ein ähnliches Verhalten der Reninaktivität. Auch bei der vierten Versuchsperșon (Abb. 5) wurde ein deutliches Maximum der Reninaktivität ermittelt, wobei jedoch vermerkt werden muß, daß fünf Tage später eine Blutung auftrat. D̈ie „Leeraktivität", die in Abwesenheit von zugesetztem Renin= substrat (Katzenplasma) bestimmt wurde, verhielt sich ähnlich wie die Reninaktivität im Serum.

\section{Versucbe zur Erklärung der "Leeraktivität"}

Nachdem sich gezeigt hatte, daß sowohl bei Frauen während des menstruellen Zyklus als auch besonders bei Schwangeren eine deutliche "Leeraktivität" nachweisbar war, ergab sich die Frage, worauf die „Leeraktivität ${ }^{\text {‘c }}$ zurückzuführen ist. In diesem Zusammenhang erschien es von Interesse, auch bei männlichen 


\section{Hochwertige Laborgeräte haben einen Namen: ORIGNALIKA}

\begin{abstract}
Wo im Labor Dispergierprobleme auftauchen, gibt es immer eine Lösung: ULTRA TURRAX Hochleistungs-

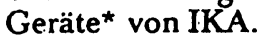

Das bewährte Stator-Rotor-Prinzip ermöglicht höchste Dispergierwirkungen. Bei Emulsionen und Suspensionen ebenso wie beim Zerfasern oder bei der Reaktionsbeschleunigung von chemischen oder biologischen Prozessen.

ULTRA TURRAX Hochleistungsgeräte werden mit allem fertig (von $1 \mathrm{ml}$ bis

$40 \mathrm{ltr}$. Stoffmenge - natürlich hat IKA auch Maschinen, die bis zu einer Leistung von $60 \mathrm{t} / \mathrm{h}$ gehen). Sie haben keine Dispergierprobleme mehr.

ULTRA TURRAX
\end{abstract}

Hochleistungs-Dispergiergeräte * nach Prof. Willems

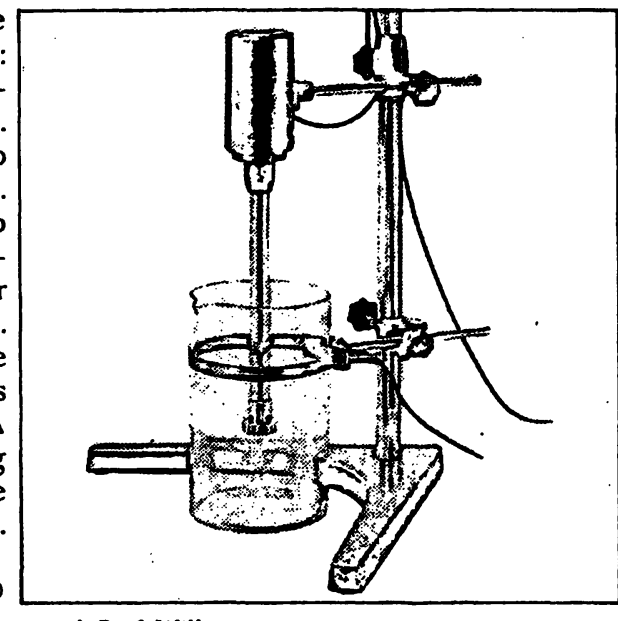

Überall, wo gerührt, geknetet, dispergiert, temperiert und analysiert wird, gilt ORIGINAL IKA als Maßstab für Qualität. Ein breites Geräteprogramm - im engen Kontakt zu Industrie und Forschung entwickelt - wird allen Anforderungen gerecht.

Neben unserer Anwendungstechnischen Abteilung stehen Ihnen über 70 Beratungsbüros im In- und Ausland sowie der qualifizierte Labor-Fachhandel zur Verfügung. Auf Wunsch informieren wir Sie über unsere Produktgruppen.

7 Janke \& Kunkel KG.

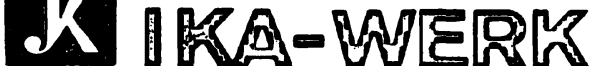
7813 Staufen bei Freiburg, Postfach 44 Tel.: (07633) 6036, Telex: 0772922

\section{Das neue digitale Photometer-System von VITATRON müssen Sie kennenlernen.}

An Ihrem Arbeitsplatz, in Ihrem Labor führen wir diese

moderne VITATRON-Neuentwicklung vor;

selbstverständlich unverbindlich und kostenlos.

Über die vielen Anwendungsmöglichkeiten informieren wir Sie gern.

Kreuzen Sie die Kennziffern an - wir kommen!

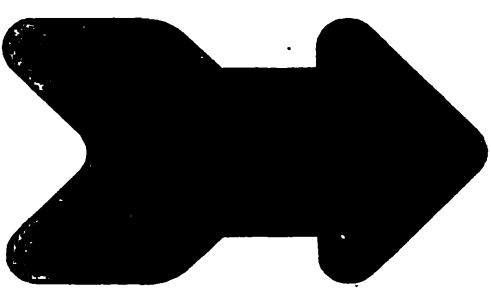

VITATRON GMBH

5062 Forsbach

Kirchweg 6

Tel. 02205/5269

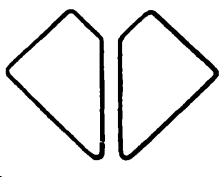

VITATRON

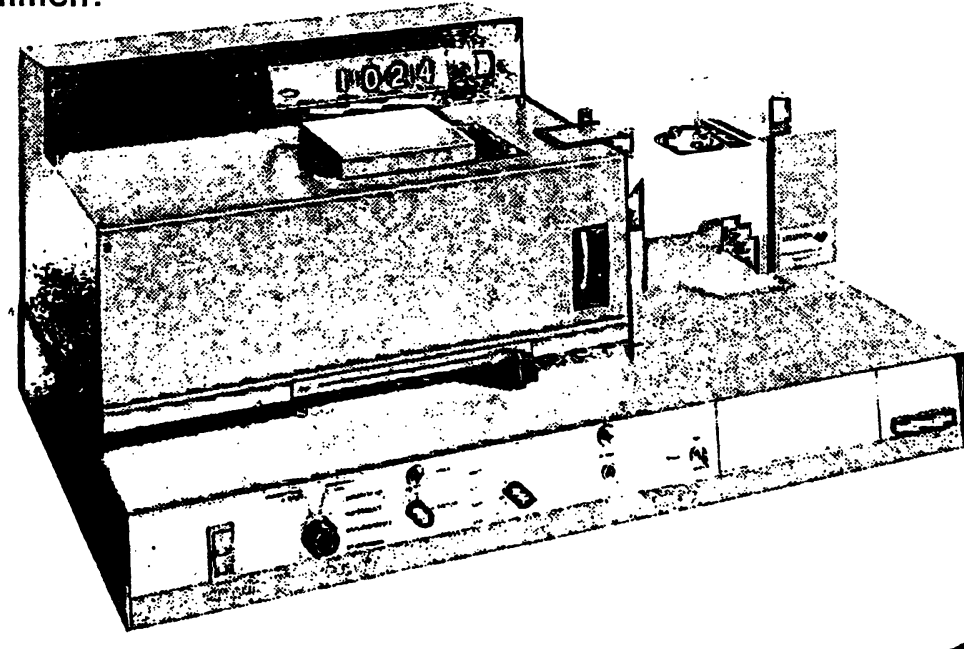




\section{aber ohne Allüren!}

\section{UV-VIS-SPEKTRALPHOTOMETER}

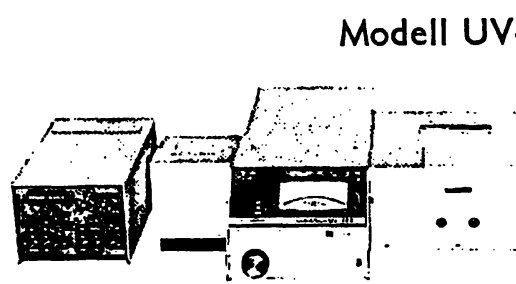

Preise frei Haus

Grundgerät UV-200

Schreiber U-125 MU

\begin{abstract}
unverzollt
\end{abstract}

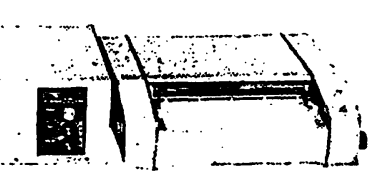

DM 12950, -

verzollt
DM 13940, -

DM 3050,-
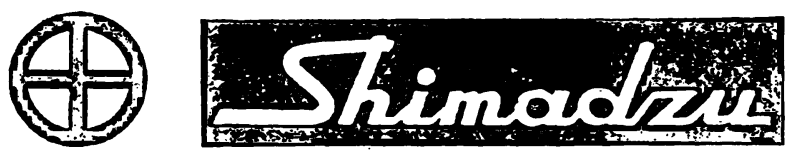

Kyoto/Japan

\section{Leistungsmerkmale und Spezifikation}

- Wellenlängenbereich $195-860 \mathrm{~nm}$

- Lin. Anzeige von Extinktion und Transmission mit eigenem Schreiber: $E=0-0,1 ; 0-0,2 ; 0-0,5 ; 0-1$; $0-2 . \mathrm{T}=0-10 \% ; 0-20 \% ; 0-50 \% ; 0-100 \%$

- Absolut symmetrisches Zweistrahl-System

- Keine Halbspiegel - keine Linsen

- Spektralbandweite 0,$25 ; 0,5 ; 1,0$ und $2,0 \mathrm{~nm}$

- Streulicht weniger als $0,1 \%$ bei $220 \mathrm{~nm}$

- $100 \%$-Linie $\pm 1 \%$ - keine Justierung notwendig

- Null-Linie ist über den gesamten Bereich verschiebbar (Differenzspektren!)

- Solid-State Elektronik mit integr. Schaltungen

- Mikromessungen ohne spezielle Halter

- Ausgangssignal $100 \mathrm{mV}$, Netzanschluß $220 \mathrm{~V}, 50 \mathrm{~Hz}$

- Umfangreiches Zubehör ist kombinierbar

Auf Wunsch Probemessungen in Ihrem Labor! Bitte fordern Sie ausführliche Unterlagen an!

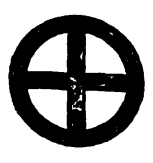

Shimadzu (Europa) GmbH

4000 Düsseldorf - Königsallee 48

Telefon (0211) 320175 - Telex 08581377

Sie gewinnen Zeit für sich und Ihre Patienten:

mit dem soeben erschienenen

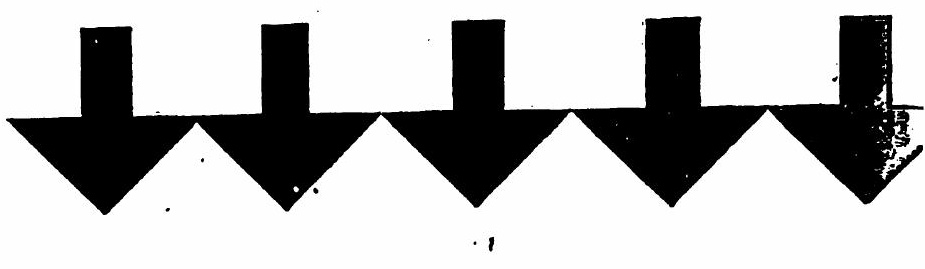

\section{Handbuch der}

\section{Praxisrationalisierung}

von Dr. med. HANS-JÜRGEN FRANK-SCHMIDT

und Professor Dr. Dr. EMIL HEINZ GRAUL

564 Seiten mit 406 Fotos, Zeichnungen und

Vordrucken sowịe zahlreichen Tâbellen, Formularen und Vertragswerken, Plastikeinband, DM 110,-

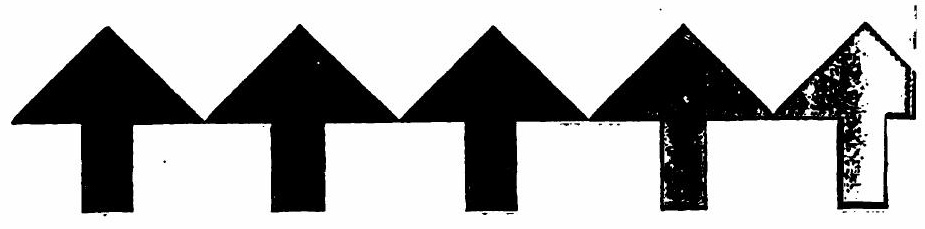

Da kein Arzt alle organisatorischen und technisch Möglichkeiten überschauen und erst recht nicht $t$ urteilen kann und nicht erșt teuere und bittere Erfé rungen selbst machen will, wird er sich des Rates v Standeskollegen bedienen, die das Angebot kenn und eine Auswahl treffen. Die Auswahl durch die $V$ fasser erfolgte ohne kommerzielle Interessen.

Der hohe Gebrauchswert des Handbuches liegt dar daß es optimale Problemlösungen beispielhaft $d$ stellt. Das gesamte Angebot an Dienstleistungen, ( ganisationsformen und Geräten wird erschlossen.

Aus dem Inhalt:

Vor der Planung der Niederlassung: Steuerplanung Die Planung und Finanzierung der Praxis

Leasing und was der Arzt davon wissen muß

Die Mieten einer Praxis

Der rationelle Grundriß für einen Praxisneubau

Allgemeine Baumaßnahmen für Neubauten, Umbaut

Anbauten und Praxiserweiterung

Gedanken zur Innenarchitektur einer Praxis:

Mobiliar, Büromittel, Labor, u. ähnl.

Die Ankündigung der Niederlassung

Die Finanzplanung nach der Niederlassung u. v. a.

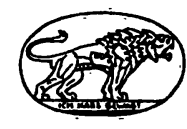

J. F. LEHMANNS VERLAG MUNCH 


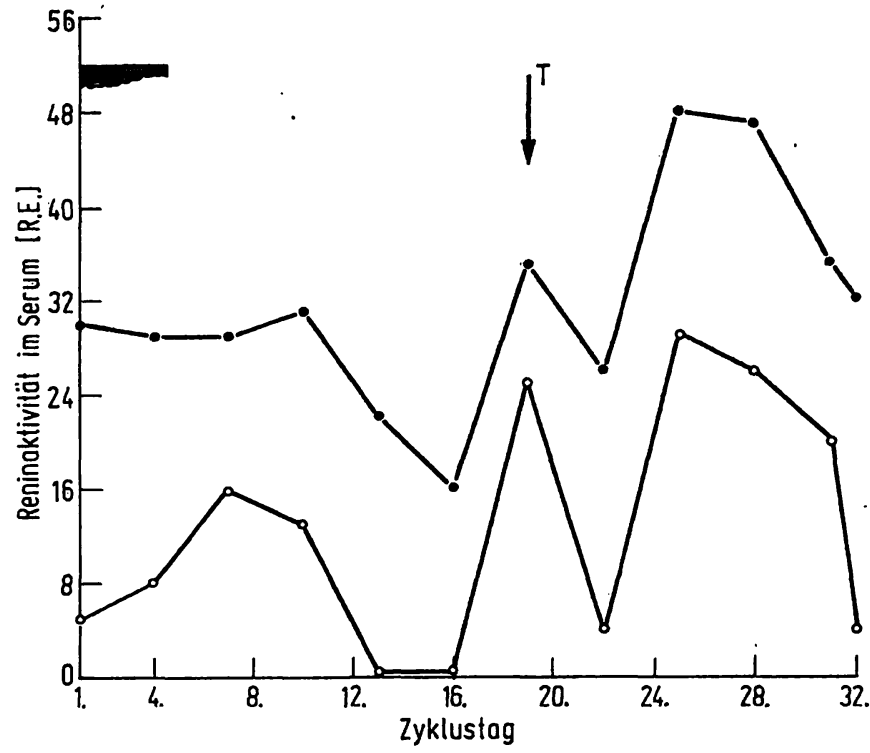

Abb. 2

Verhalten der Reninaktivität im Serum (C-O) sowie der „Leeraktivität" ( $\mathrm{O}-\mathrm{O}$ ) im Serum bei einer 23 jährigen Frau während eines 32 tägigen Menstruationszyklus. Einzelheiten über die Bestimmung der Reninaktivität vgl. Methodik. $\mathrm{T}=$ Anstieg der Basaltemperatur. Methodicion

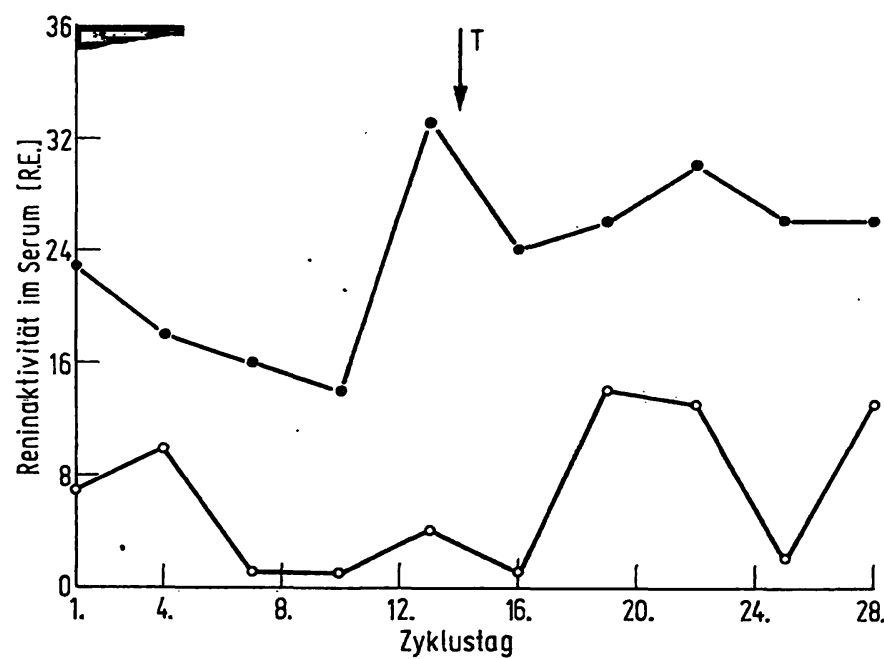

Abb. 3

Verhalten der Reninaktivität ( - - ) sowie der ,Leeraktivität" $(\mathrm{O}-\mathrm{O}$ ) im Serum bei einer 23jährigen Frau während eines 28-tägigen Menstruationszyklus. Einzelheiten über die Bestimmung der Renin aktivität vgl. Methodik. $T=$ Anstieg der Basaltemperatur. Menstruation

Normalpersonen dàs Verhalten der „Leeraktivität“ zu prüfen. Die Ergebnisse dieser Versuche sind in Tabelle 1 dargestellt. Sie zeigen, daß die „Leeraktivi-

Tab. 1

Verhalten der Reninaktivität und der ,Leeraktivität“ im Serum von acht männlichen Normalpersonen (Alter 23-27 Jahre). Einzelheiten über die Bestimmung der Reninaktivität vgl. Methodik. Bei der Bestimmung der "Leeraktivität" wurde den Inkubationsansätzen statt Reninsubsträt (Katzenplasma) eine 0,9proz. NaCl-Lösung zugesetzt. R. E. = Renin-Einheit

\begin{tabular}{lcc}
\hline Versuchsperson & $\begin{array}{c}\text { Reninaktivität } \\
\text { im Serum (R. E.) }\end{array}$ & $\begin{array}{c}\text {,Leeraktivität`` } \\
\text { im Serum (R. E.) }\end{array}$ \\
\hline B. O. & 14 & 0 \\
H. F. & 20 & 8 \\
R. S. & 21 & 6 \\
P. B. & 22 & 10 \\
G. O. & 30 & 14 \\
D. K. & 31 & 12 \\
W. G. & 36 & 6 \\
E. G. & 36 & 30 \\
\hline
\end{tabular}

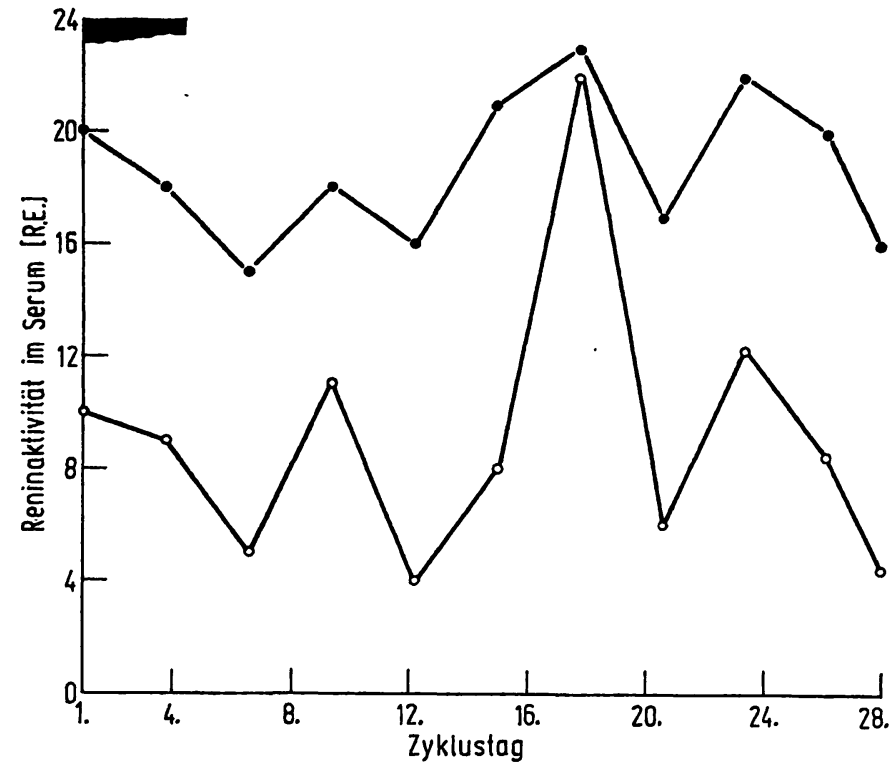

Abb. 4

Verhalten der Reninaktivität (@-O) sowie der "Leeraktivität" (O-O) im Serum bei einer 22-jährigen Frau während eines 30-tägigen Menstruationszyklus. Einzelheiten über die Bestimmung der Reninaktivität vgl. Methodik. Wenstruation

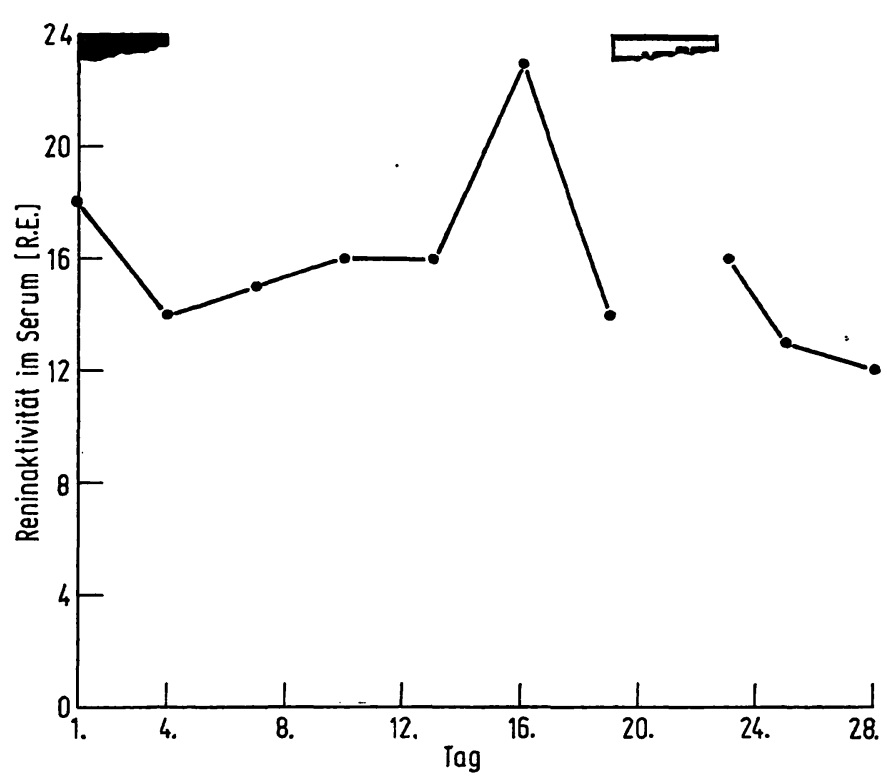

Abb. 5

Verhalten der Reninaktivität im Serum bei einer 18-jährigen Frau

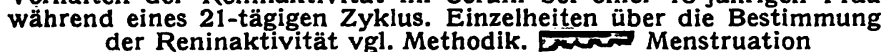

täten" bei den männlichen Normalpersonen in der gleichen Größenordnung liegen wie bei den Frauen während des Menstruationszyklus.

Folgende Ursachen kommen für das Auftreten der "Leeraktivitäten" nach 20 stdg. Inkubation der dialysierten Serumproben in Frage:

(1) Endogenes Angiotensin II wird während der Dialyse des Serums nicht vollständig entfernt.

(2) Pressorische Substanzen, die nicht aus dem ReninAngiotensin-System stammen, wie z. B. Katecholamine, sind in den dialysierten Serumproben vorhanden.

(3) Das endogene Reninsubstrat wird während der Dialyse bei $\mathrm{pH}$ 3,3 nicht vollständig inaktiviert. Um 
Tab. 2

Vergleich der Reninaktivität und der "Leeraktivität" im Serum nach Inkubation mit der pressorischen Aktivität im Serum vor Inkubation bei drei Schwangeren $\left(S_{2}-S_{8}\right)$ und drei weiblichen Normalpersonen $\left(N P_{1}-N P_{3}\right)$. Einzelheiten über die Bestimmung der Reninaktivität vgl. Methodik. Bei der Bestimmung der "Leeraktivität" wurde den Inkubationsansätzen statt Reninsubstrat '(Katzenplasma) eine 0,9proz. NaCl-Lösung zugesetzt. Zur Messung der pressorischen Aktivität im Serum vor Inkubation wurde das Serumdialysat in gleicher Weise aufgearbeitet wie die Inkubationsansätze R. E. = Renin-Einheit

\begin{tabular}{lccc}
\hline Versuchsperson & $\begin{array}{c}\text { Reninaktivität } \\
\text { im Serum } \\
\text { (R. E.) }\end{array}$ & $\begin{array}{c}\text { "Leeraktivität" } \\
\text { im Serum } \\
\text { (R. E.) }\end{array}$ & $\begin{array}{c}\text { Pressorische } \\
\text { Aktivität } \\
\text { im Dialysat }\end{array}$ \\
\hline
\end{tabular}

\begin{tabular}{lrrl}
\hline$S_{1}$ & 66 & 12 & 0 \\
$S_{2}$ & 150 & 120 & 0 \\
$S_{3}$ & 152 & 152 & 0 \\
$N_{1}$ & 23 & 24 & 0 \\
$N_{2}$ & 29 & 16 & 0 \\
$N_{3}$ & 35 & 25 & 0 \\
\hline
\end{tabular}

festzustellen, welche der drei Möglichkeiten zutrifft, wurden die Serumproben unmittelbar nach der Dialyse aufgearbeitet und auf pressorische Aktivität untersucht. Wie Tabelle 2 zeigt, ließ sich weder bei drei Schwangeren noch bei drei weiblichen Normalpersonen eine meßbare pressorische Aktivität in den Serumproben unmittelbar nach der Dialyse nachweisen. Daraus kann geschlossen werden, $\mathrm{da} B$ die „Leeraktivität“ durch unvollständige Inaktivierung des endogenen Reninsubstrats während der Dilayse bei pH 3,3 bedingt ist. In der Tat war nach Verlängerung der Dialysedauer auf 45-96 Stdn. keine „Leeraktivität“ im Serum mehr nachweisbar (Tab. 3); unabhängig davon nahm jedoch auch die Reninaktivität im Serum ab.
Tab. 3

Verhalten der Reninaktivität und der "Leeraktivität" im Serum von chwangeren (Mischseren 1 und 2) sowie von männlichen (Mischserum 3) und weiblichen (Mischserum 4) Normalpersonen in Abhängigke von der Dauer der Dialyse bel pH 3,3. Alle Mischseren enthielten dre Elnzelseren. Einzelheiten uber die Bestimmung der Reninaktivität vgl. Methodik. Bei der Bestimmung der "Leeraktivität" wurde den Inkubationsansätzen statt Reninsubstrat (Katzenplasma) eine 0,9 proz. $\mathrm{NaCl}-\mathrm{Lösung}$ zugesetzt R. E. = Renin-Einheit

\begin{tabular}{cccc}
\hline Mischserum & $\begin{array}{c}\text { Dauer der } \\
\text { Dialyse bei } \\
\text { pH 3,3 (h) }\end{array}$ & $\begin{array}{c}\text { Reninaktivität } \\
\text { im Serum } \\
\text { (R. E.) }\end{array}$ & $\begin{array}{c}\text { "Leeraktivität" } \\
\text { im Serum } \\
\text { (R. E.) }\end{array}$ \\
\hline 1 & 24 & 144 & 140 \\
& 45 & 55 & 10 \\
& 68 & 37 & 0 \\
2 & 96 & 32 & 0 \\
& 24 & 78 & 5 \\
& 45 & 44 & 1 \\
3 & 68 & 30 & 6 \\
& 96 & 23 & 0 \\
& 24 & 17 & 0 \\
4 & 45 & 10 & 9 \\
& 68 & 6 & 0 \\
& 96 & 27 & 0 \\
& 24 & 16 & 8 \\
\hline
\end{tabular}

\section{Diskussion}

In der vorliegenden Arbeit konnte gezeigt werden, daß bei gesunden Frauen die Reninaktivität im Serum sowohl zur Zeit der Ovulation als auch während der Lutealphase ein Maximum aufweist. Hinwieise auf eine erhöhte Reninaktivität hatten sich bereits früher ergeben $(2,8,9)$; der Nachweis eines zusätzlichen Maximums der Reninaktivität zum Zeitpunkt der Ovulation

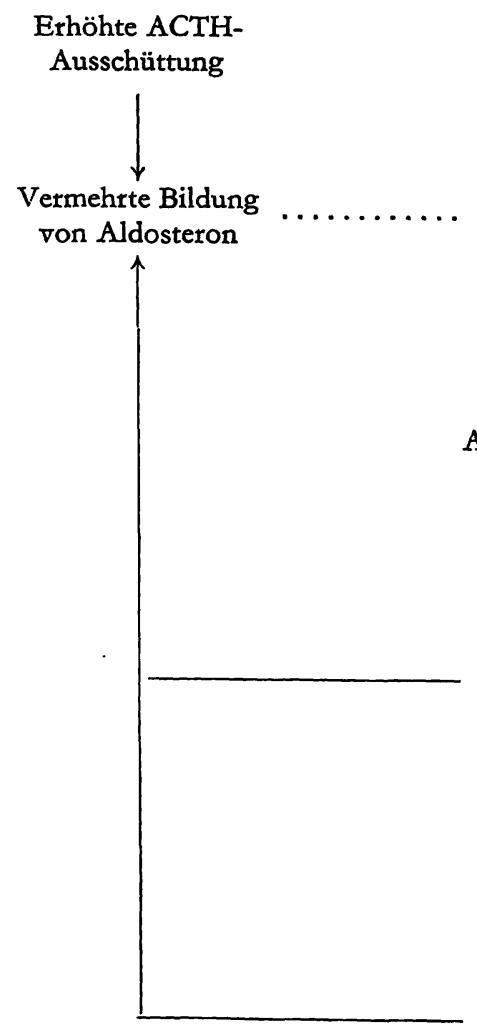

Erhöhter Östrogenspiegel

(Gravidität; Zyklus: Gipfel zur Zeit der Ovulation und in der Lutealphașe

Vermehrte Bildung von

Transportproteinen im Plasma

Vermehrte Bindung von Aldosteron

Abnahme von freiem Aldosteron im Plasma

Verminderte Rückresorption von

Natrium in distalen Tubulus

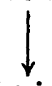

Abnahme der Natriumkonzentration im Plasma

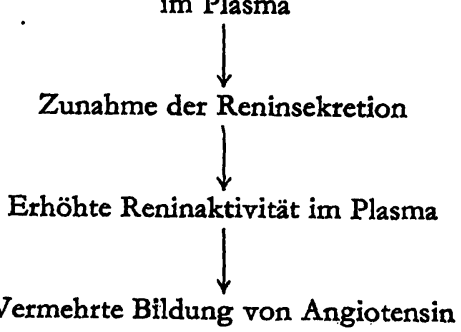

Abb. 6
Vereinfachte Darstellung der Beziehungen zwischen Renin, Aldosteron und Sexualhormonen. Erläuterungen vgl. Text

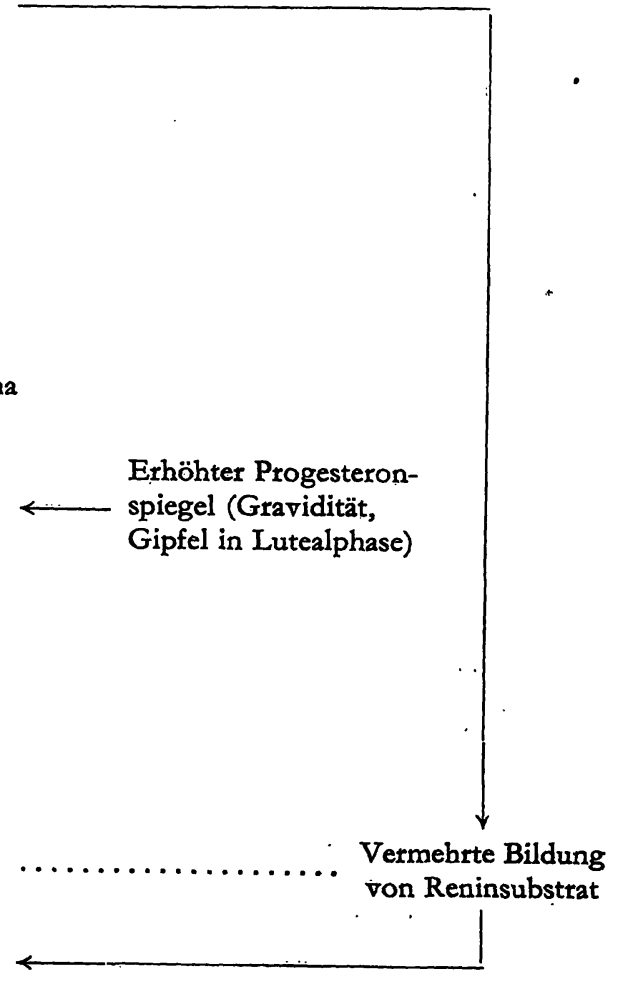

Erhöhter Progesteron piegel (Gravidität, Gipfel in Lutealphase)

Vermehrte Bildung 
war erst durch Verlaufsbeobachtungen in 2- bis 3tägigen Abständen während des menstruellen Zyklus möglich.

Das hier beobachtete Verhalten der Reninaktivität im Serum während des menstruellen Zyklus kann durch die gleichzeitigen Veränderungen im Sexualendokrinium wie folgt erklärt werden (vgl. Abb. 6): Als Folge der vermehrten Sekretion von Östrogenen - einmal zur Zeit der Ovulation, zum anderen während der Lutealphase des Zyklus - kommt es zu einer Vermehrung von Transportproteinen im Serum (z. B. Transcortin); dadurch wird Aldosteron vermehrt gebunden, und die Konzentration an freiem - und damit biologisch wirksamem - Aldosteron im Serum nimmt ab. Durch die verminderte Rückresorption von Natrium und die damit verbundene Abnahme der Natriumkonzentration im Serum steigt die Reninsekretion an. Es resultiert eine erhöhte Reninaktivität. Möglicherweise trägt auch die vermehrte Bildung von Progesteron während der Lutealphase zu dem zweiten Maximum der Reninaktivität bei; Progesteron führt nämlich als Antagonist von Aldosteron zu einer vermehrten Natriurese (11).

Die erhöhte Reninaktivität während der Schwangerschaft, die in den eigenen Untersuchungen bestätigt werden konnte, läßt sich ebenfalls mit Hilfe der oben beșchriebenen Zusammenhänge erklären. Als Folge der stark erhöhten Östrogenproduktion während der Schwangerschaft wird zusätzlich vermehrt Reninsubstrat gebildet (5); dies könnte unter der Annahme, daß bei stark erhöhter Reninaktivität keine Substratsättigung mehr vorliegt, einen weiteren Einfluß auf die Bildung von Angiotensin ausüben. Im Gegensatz zur Schwangerschaft scheint die Konzentration von Reninsubstrat im menstruellen Zyklus bei der Angiotensinbildung keine Rolle zu spielen (9). Die vermehrte Bildung von Aldosteron während der Schwangerschaft, die hauptsächlich auf Veränderungen im Renin-An-
giotensin-System zurückzuführen ist, zum Teil aber auch durch eine erhöhte ACTH-Ausschüttung bedingt sein kann, dürfte infolge der erhöhten Bindung von $\mathrm{Al}$ dosteron an Plasmaproteine (vgl. Abb. 6) biologisch nicht relevant sein. In diesem Zusammenhang sei angefügt, daß synthetische Östrogene (3-Methoxy-17 $\alpha$ äthinyl-1,3,5 (10)-östratrien-3,17 $\beta$-diol) sowie ÖstrogenGestagen-Kombinationen (3-Methoxy-17 $\alpha$-äthinyl-1,3,5 (10)-östratrien-3,17 $\beta$-diol und $17 \alpha$-Äthinyl-17 $\beta$-hydroxy5 (10)-östren-3-on) zu einer vermehrten Bindung von Aldosteron an Plasmaproteine führen $(12,13)$.

Unabhängig von der Frage, ob im Plasma von Normalpersonen Reninsubstrat in Sättigungskonzentrationen vorliegt $(14,15)$ oder nicht (5), ist die Erhöhung der Konzentration des Reninsubstrats im Schwangerenserum von methodischem Interesse, denn die teilweise sehr hohen "Leeraktivitäten" sind darauf zurückzuführen, daß die erhöhten Mengen an Reninsubstrat während der Dialyse der Seren bei pH 3,3 nicht vollständig inaktiviert werden. Diese Tatsache scheint jedoch keine wesentliche Bedeutung $z \mathrm{u}$ haben, da endogenes Reninsubstrat und exogenes Reninsubstrat (Katzenplasma) nicht in additiver Weise zur Freisetzung von Angiotensin beitragen. Diese unerwartete Tatsache ist offenbar auf folgendes zurückzuführen: (1) Menschliches Renin hat zum Reninsubstrat im Katzenplasma die gleiche Affinität wie zum Reninsubstrat im Plasma des Menschen (16); (2) es besteht eine Kompetition $z$ wischen den beiden genannten Reninsubstraten um das Enzym Renin (17). Somit kann die unvollständige Inaktivierung des endogenen Reninsubstrats unberücksichtigt bleiben, da die Analysenergebnisse dadurch nicht beeinflußt werden. Im übrigen würde sich eine Verlängerung der Dialysedauer - mit dem Ziel der vollständigen Inaktivierung des endogenen Reninsubstrats - ohnehin nicht empfehlen, weil dabei auch eine Inaktivierung des Enzyms erfolgt.

\section{Literatur}

1. Brown, J. J., D. L. Davies, P. B. Doak, A. F. Lever und J. I. S. Robertson, Lancet $I I / 1963,900$. - 2. WINER, B. M., J. clin. Invest. 44, 1112 (1965). - 3. Genest, J., J. DE ChAMplain, R. Veyrat, R. Boucher, G. G. Tremblay, C. G. Strong, E. Korw und J. Marc-Aurele, Hypertension 13, 97 (1965). 4. Brown, J. J., D. L. Davies, P. B. Doak, A. F. Lever und J. I. S. Robertson, J. Endocr. 35, 373 (1966). - 5. Helmer, O. M. und W. E. Judson, Amer. J. Obstetr. Gynec. 9, 9 (1967). 6. Geelhoed, G. W. und A. J. VAnder, J. Clin. Endocr., Springfield 28, 412 (1968). - 7. Gokdon, R. D., S. Parsons und E. M. Symonds, Lancet $I / 1969$ 347. - 8. Brown, J. J., D. L. Davies, A. F. Lever und J. I. S. Robertson, Brit. med. J. 2, 1114 (1964).
9. Skinner, S. L., E. R. Lumbers und E. M. Symonds, Clin. Sci. 36, 67 (1969). - 10. Kaulhausen, H., B. Fillmann und H. Breuer, diese Z. 8, 254 (1970). - 11. Laidlaw, J. C., J. L. Ruse und A. G. Gornale, J. Clin. Endocr., Springfield 22, 161 (1962). 12. Meyer, C. J., D. S. Layne, J. F. Tait und G. Pincus, J. clin. Invest. 40, 1663 (1961). - 13. LAYNe, D. S., C. J. MEYER, P. S. Vaishwanar und G. Pincus, J. Clin. Endocr., Springfield 22, 107 (1962). - 14. Gould, A. B., L. T. SkEgGS und J. R. KAHN, Laborat. Invest. 15, 1802 (1966). - 15. HAAs, E. und H. Goldblatt, Circulat. Rc6. 20, 45 (1967). - 16. Helmer, O. M. und W. E. Judson, Circulation 27, 1050 (1963). - 17. Poulsen, K., Scand. J. clin. Laborat. Invest. 21,49 (1968).

Prof. Dr. H. Breuer

Inst. f. Klin. Biochemie der Rhein. Fried.-Wilhelm-Univ. 53 Bonn 1

Venusberg 